\title{
EMPLOYMENT OF PEOPLE WITH DISABILITIES: IMPLICATIONS FOR HUMAN RESOURCE MANAGEMENT PRACTICES
}

\author{
P Gida, Wits Business School, South Africa; K Ortlepp, School of Management, University of \\ KwaZulu-Natal, South Africa
}

\begin{abstract}
Purpose: The purpose of this paper is to, firstly, present the findings of an empirical study in which the human resource management practices associated with the employment of people with disabilities were investigated. The human resource management challenges related to employment of people with disabilities were also identified in the empirical study and are presented in this paper. A further purpose of this paper is to propose a number of recommendations focused on human resource management practices and principles aimed at assisting managers and human resource management specialists in their endeavours to effectively deal with the employment of people with disabilities.
\end{abstract}

Design/Methodology/Approach: This paper is based on an empirical study in which interviews were conducted with respondents from 19 different organisations identified in the Financial Mail's 'Top 100 Organisations in South Africa' list.

Findings: The findings from the empirical study suggest that very few organisations are dealing with the employment of people with disabilities as a priority in their equity strategies. Where attention is being given to this issue, respondents seem to either address it as a legal compliance issue or a social responsibility 'project'. Furthermore, very little has been done to review current human resource management practices to determine whether they are discriminatory towards people with disabilities. Based on the insights gained from these findings and in line with best practice principles identified in the relevant literature, a number of recommendations focusing on human resource management practices and principles in relation to the employment of people with disabilities are proposed.

Implications: This paper provides a number of practical steps to consider as part of an organisation's response to equity strategies related to the employment of people with disabilities.

Originality/Value: In the Employment Equity Commission's Annual Report (2003-2004), it is noted with concern that there is no indication of real change being achieved in the employment of people with disabilities. Furthermore, there is a dearth of empirical research in this field and thus the exploration of issues related to the employment of people with disabilities is clearly an area requiring urgent attention in terms of South Africa's transformation agenda.

Key words and phrases: people with disabilities, employment equity, challenges, human resource management practices

\section{INTRODUCTION}

South Africa's present government has placed great emphasis on the promotion of equality in society. Significant gains have been achieved at the level of policy and legislation in the twelve years of South African democracy. The Employment Equity Act (EEA), No. 55 (Republic of South Africa, 1998) was promulgated with the purpose of achieving equity in the workplace by: promoting equal opportunity and fair treatment in employment through elimination of unfair discrimination; and implementing affirmative action measures to redress the disadvantages in employment experienced by designated groups, to ensure their equitable representation in occupational categories and levels in the workforce. In particular, the EEA (Republic of South Africa, 1998) stipulates that organisations that have 50 or more employees or more than specified financial turnover must conduct an audit of their formal and informal policies and practices to identify any barriers to the employment of people from designated groups and directs employers to implement affirmative action measures to redress the discrimination. People with disabilities are part of the designated group identified in the EEA (Republic of South Africa, 1998). It is estimated that between 5 and 12 percent of South Africans are moderately or severely disabled (Republic of South Africa, 1997). To date, as reported in the Employment Equity Commission Annual Report: 2003-2004 (Republic of South Africa, 2004), although the numbers are still low, there is a greater representation of women and black people than before on the executive boards of South African organisations. However, there is no indication of real change for people with disabilities as is highlighted in the following quote from the 2003-2004 Employment Equity Commission's Annual Report (Republic of South Africa, 2004:12) "Of particular concern to the Commission is the fact that employers are not paying enough attention to this dimension of employment equity." The in-depth exploration of issues related to the employment of 
people with disabilities is clearly an area requiring urgent attention in terms of South Africa's transformation agenda.

In response to this need, the objective of this paper is to present the findings of an empirical study in which the human resource management practices associated with the employment of people with disabilities were investigated in a sample of the Top 100 Organisations in South Africa. The human resource management challenges related to employment of people with disabilities were also identified in the empirical study and are presented in this paper. Within the context of these findings, a further objective of this paper is to propose a number of recommendations focused on human resource management practices and principles aimed at assisting managers and human resource management specialists in their endeavours to effectively deal with the employment of people with disabilities.

It is believed that this paper will contribute in assisting organisations in the following ways:

- To examine their approach towards people with disabilities and align their practices to the guidelines laid down in the Code of Good Practice for the Employment of People with Disabilities (Republic of South Africa, 2002).

- To further the understanding of the spirit and achievement of the objectives of the EEA (Republic of South Africa, 1998), in terms of moving beyond the 'numbers game' to a meaningful work-life experience for people with disabilities.

- To enhance the understanding of principles related to creating a positive and accommodating work environment in which diversity is respected and valued.

- To explore the options available in managing people with disabilities in the workplace and the modifications that need to be effected in order to fully integrate people with disabilities in the workplace.

\section{LITERATURE REVIEW}

The EEA (Republic of South Africa, 1998) defines people with disabilities as "people who have a longterm or recurring physical or mental impairment which substantially limits their prospects of entry into, or advancement in, employment". The Code of Good Practice on the Employment of People with Disabilities (Republic of South Africa, 2002) further clarifies the terms used in the definition above. 'Long-term' means that the impairment has lasted or is likely to persist for at least twelve months. A recurring impairment is one that is likely to happen again and is likely to be substantially limiting. An impairment may be physical or mental. A 'physical' impairment means a partial or total loss of a bodily function or part of the body, and includes sensory impairments such as being deaf or hearing impaired, deaf-blind, or visually blind. A 'mental' impairment is a clinically recognised condition or illness that affects a person's thought process, judgment or emotions. An impairment is substantially limiting if it limits a person's ability to perform essential job tasks.

In the South African 2001 Census, it was noted that, of the 44.8 million people counted, 2.3 million people (5\% of the total population) were reported as being disabled. Furthermore, looking at different types of disability, $577000(1.3 \%$ of the total population) had a visual disability, while $558000(1.2 \%)$ had a physical disability, $314000(0.7 \%)$ had a hearing impairment, $269000(0.6 \%)$ had an emotional disability, $206000(0.5 \%)$ had an intellectual impairment, and $75000(0.2 \%)$ had a communication disability (Lehohla, 2003).

Historically, the vast majority of people with disabilities in South Africa have been excluded from education, housing, transport, employment, information and community life (McClain \& Lawrence, 2002). They have been prevented from exercising fundamental political, economic, social, cultural and development rights. These injustices were reinforced by the inequalities of the apartheid system (McClain \& Lawrence, 2002). Related to this, it is argued that the way in which society conceptualises disability is of fundamental importance to the identification and elimination of unfair discrimination against people with disabilities, particularly in the workplace (South African Federal Council on Disability, 1999). According to Thomas and Hlahla (2002), society still largely perceives disability as a medical problem. In the disability rights movement, there is a strong acknowledgement that a person's disability is exacerbated when $s /$ he is not regarded first as a person and only then taking into account his/her physical or mental impairments (Russell, 2000). In the South African Human Rights 
Commission Report of 2002 (McClain \& Lawrence, 2002), it is noted that a person is disabled if the world at large will not take into account their physical, sensory or mental differences. Most of the dayto-day problems that people with disabilities face are caused by the fact that they live in a hostile, disabling world which is largely designed to suit able-bodied people.

As a result, people with disabilities have long recognised that discrimination is not only an individual or attitudinal problem, but a social creation entrenched within institutions, organisations and processes that constitute the total society (Olivier, 1996). According to the South African Human Rights Commission Report of 2002 (McClain \& Lawrence, 2002), the extent and experience of disability is to a large extent determined by how much the person's environment prevents that individual from taking part in community life on an equal level with others. Disability is imposed by society when a person with impairment is denied access to full economic and social participation. Society fails either physically or culturally, to accommodate the rights and needs of individuals with impairments. Added to this, widespread ignorance, fear and stereotypes cause people with disabilities to be unfairly discriminated against in society and the workplace (Barnes \& Mercer, 2003). As such, people with disabilities around the world, have begun to engage society in addressing the issue of fundamental human rights (Republic of South Africa, 1997).

Between 1993 and 2000, eight important Acts were passed by the South African Parliament, which cumulatively had a significant impact in the workplace and the employment practices. There are specific references in some of these Acts to people with disabilities, whilst in other Acts the changes affect all employees. In 2002, the South African government introduced the Code of Good Practice on the Employment of People with Disabilities (Republic of South Africa, 2002) as an annexure to the EEA (Republic of South Africa, 1998) so as to provide guidance and support to employers and employees regarding the unique challenges associated with the promotion of equal opportunities and fair treatment for people with disabilities as required by the EEA. (Republic of South Africa, 1998). The Code is not a summary of the law, and it does not create additional rights and obligations. Failure to observe the Code does not, by itself, render a person liable in any proceedings. However, when the courts and tribunals interpret and apply the EEA (Republic of South Africa, 1998), they must also consider the Code. To further enhance the support provided to employers in this regard, the Department of Labour has recently introduced the Technical Assistance Guidelines on the Employment of People with Disabilities (Republic of South Africa, 2005). In principle, then, the South African authorities have taken major steps to place the role of the disabled in society and the workplace firmly onto the nation's redress and transformation agenda.

Advances in technology have improved the chances of being employable for people with disabilities (Barnes \& Mercer, 2003) and if employers are willing to make certain adjustments in the workplace to reasonably accommodate people with disabilities, people with disabilities offer new talent that has not yet been fully utilised (Silver, 2000). Thomas and Hlahla (2002), in agreement with Cronan (2000) and Silver and Koopman (2000), argue that, from a financial perspective, employers in South Africa can no longer afford to exclude people with disabilities from the labour market. This is mainly due to the skill shortage created by the emigration of skilled managers and the competition between organisations to be viewed as an 'employer of choice', a factor which impacts on the attraction and retention of talented employees (Thomas \& Hlahla, 2002). However, it appears from the literature reviewed that, while employers may have positive attitudes towards hiring people with disabilities, in principle, these do not correlate with the low numbers of people with disabilities that are employed in the open labour market, in practice as reported in the Employment Equity Commission Annual Report of 2003-2004 (Republic of South Africa, 2004). This may well be due to the challenges associated with the employment of people with disabilities. For instance, accommodations that entail substantial cost have been noted to slow down the employment of people with disabilities (Silver \& Koopman, 2000). Furthermore, it has been argued that disabled people may have a lesser degree of education due to restricted opportunities and, therefore, are not as likely to be hired (Neufeldt \& Albright, 1998). Insufficient information about disability, rather than prejudice itself, has also been found to be a significant obstacle to eliminating discrimination in the employment of people with disabilities (Baldwin \& Johnson, 2000).

While the employment of people with disabilities has received considerable attention in labour legislation and supporting documents of principle, there remains a dearth of empirical research focusing on the experiences of both the employees with disabilities and their employers in relation to the challenges and benefits associated with employment of people with disabilities. An investigation into these and other issues surrounding the employment of people with disabilities is clearly needed. As Stelzner (2003:2) 
has stated, "Changes to various laws have created rights and opportunities for people who suffer from disabilities, especially in the context of employment. It is only a matter of time before cases involving disability rights start hitting the headlines as they have done in some countries overseas."

\section{RESEARCH METHODOLOGY}

The strategy proposed in this paper is based on the findings from the empirical study. The research design adopted and the sample comprising this empirical study are outlined accordingly.

\section{Research Design}

A qualitative research design was adopted in which in-depth semi-structured interviews were used to collect data.

\section{Sample}

The population for this study comprised all organisations listed in the 'Top 100 Organisations' in South Africa. The 'Top 100 Organisations' list is determined through independent research conducted by the University of Pretoria's Bureau of Financial Analysis for the Financial Mail. The organisations were assessed on both quantitative and qualitative measures. The quantitative measures used include financial variables like turnover, total assets, market capitalisation, equity funds, net profit, pre-tax profit, earning per share, dividend per share and debt. On the qualitative side, the following elements were assessed: corporate governance, investor communication, strength of management, transformation, investability, industry profit prospects, and individual company profit. The reason for combining quantitative and qualitative measurements was that purely quantitative measurements are based on historic data and they do not reflect South Africa's business priorities, such as corporate governance and transformation (Theobald, 2003). Organisations listed as part of 'The Top 100 Organisations' were the population chosen for this study because it was assumed that they consider transformation, in relation to equity issues, as a key business priority.

The size of the sample was limited, firstly by the actual number of organisations that employ people with disabilities and secondly, by the willingness of those organisations to participate in this study. Utilising a topdown approach, organisations were contacted to determine whether the company employed people with disabilities and, if this was the case, then whether the company's contact person would be willing to participate in the study. Organisations differ in the way they are structured and therefore also differ in terms of ownership of their employment equity or diversity management programmes. In some organizations, the Human Resources Executive is directly responsible for this function while, in others, there is a designated person that only looks at employment equity and/or management of diversity. In each of the organisations that participated in this study, only the person directly responsible for employment equity or diversity management was interviewed.

The organisations that were ranked as the top thirty out of 'The Top 100 Organisations' were first approached. If, for some reason, one of these organisations was not able to participate in the study, then the next company on the list was approached. In total, 73 organisations were approached. Of these, only 19 were able and willing to participate in the interview process.

\section{FINDINGS: PRESENTATION AND DISCUSSION}

The findings related to each question are presented in tabular format and are discussed briefly thereafter.

\section{Percentage of the Organisation's Workforce Comprising Employees with Disabilities}

The first aspect explored in the interviews was the extent to which the participating organisations are employing people with disabilities. Table 1 outlines the percentage representation of people with disabilities employed in the organisations that participated in this study. 
Table 1: Percentage representation of people with disabilities

\begin{tabular}{|l|l|l|}
\hline Below 1\% & Between 1\% and 2\% & Above 2\% \\
\hline 13 & 3 & 3 \\
\hline
\end{tabular}

Although most of the organisations indicated that people with disabilities occupy positions across the different levels in the organisation, most of these employees are in lower-level jobs, especially clerical and administrative positions. Only two organisations reported having a person with a disability occupying a top management position.

It is apparent from the results of the study presented in Table 1 that the target set by government for people with disabilities to comprise $2 \%$ of the total workforce by 2005 had not yet been achieved. This reflects the observation made in the Employment Equity Commission's Annual Report of 2003-2004 (Republic of South Africa, 2004) where it is emphasised that corporate South Africa still has a long way to meet this target. There are reasons for the slow increase in the numbers of people with disabilities in the workplace, for instance, ignorance, fear and stereotypes were reported to be the main reasons for this slow increase. In some of the interviews, it was reported that there is a tendency to want to identify certain types of positions exclusively for the appointment of people with disabilities. For example, one organisation was considering placing all people with disabilities into their call centres. The researchers would argue that, while this could be an initiative, it could lead to a further exclusion of people with disabilities because then it would not be easy to integrate into the rest of the organisation. They would be working in their own isolated area, which would also deprive the rest of the organisation of an opportunity to better understand people with disabilities, and to accept them as part of the organisation, as noted in the Code of Good Practice for the Employment of People with Disabilities (Republic of South Africa, 2002). It would further limit the opportunity for other people to appreciate the capabilities of people with disabilities, and the value they can add to the organisation. 'Herding' people with disabilities into call centres would mean that there would be limited career growth for them. This really goes against the spirit and intent of the EEA (Republic of South Africa, 1998).

\section{Existence of a Strategy or Policy Related to the Employment of People with Disabilities}

A key area of focus in the empirical study was to determine whether the participating organisations had developed a strategy or policy related to the employment of people with disabilities. Table 2 outlines the findings in this regard.

Table 2: Strategy and/or policy related to the employment of people with disabilities

\begin{tabular}{|l|l|}
\hline Nature of strategy & No. Of organisations \\
\hline $\begin{array}{l}\text { There is no strategy or policy whatsoever for the } \\
\text { employment of people with disabilities }\end{array}$ & 16 \\
\hline $\begin{array}{l}\text { The EE Plan has a section that specifically addresses } \\
\text { disability }\end{array}$ & 2 \\
\hline $\begin{array}{l}\text { A separate strategy document exists, specifically for } \\
\text { people with disabilities }\end{array}$ & 1 \\
\hline
\end{tabular}

From Table 2, it can be seen that most (16) of the organisations sampled do not have a strategy or policy document specifically for the employment of people with disabilities. Most of the organisations, however, indicated that they are currently working on a framework and policy document for the employment of people with disabilities. Currently, it would seem, organisations are dealing with the employment of people with disabilities as only one aspect of their employment equity plans rather than as a strategy based on a strong business case as proposed by Silver and Koopman (2000). Furthermore, from the results of this study, it would seem that the employment of people with disabilities has barely been addressed even at a legal compliance level by the majority of organisations in this study. Thus, to a large extent, the findings of this study support the assertions made in the literature that people with disabilities remain the most 'disadvantaged of the disadvantaged' (Silver, 2000). 


\section{Role of Senior Management in Relation to the Employment of People with Disabilities}

Table 3 gives an indication of the various roles that the leadership of the organisations consulted in this study have played in the employment of people with disabilities.

\section{Table 3: Role of senior management}

\begin{tabular}{|l|l|}
\hline Leadership role & No. of organisations \\
\hline $\begin{array}{l}\text { Leaders acknowledge the importance of disability equity and are } \\
\text { generally supportive }\end{array}$ & 6 \\
\hline CEO/ Top management initiates the process and gets HR to drive & 5 \\
\hline Completely owned and driven by HR & 4 \\
\hline Line managers are accountable for achieving set targets & 3 \\
\hline An executive manager is the sponsor of the disability strategy & 1 \\
\hline $\begin{array}{l}\text { Employment equity constitutes 20\% of performance agreements for line } \\
\text { managers }\end{array}$ & 1 \\
\hline
\end{tabular}

As can be seen from the Table 3, in many of the organisations that participated in the study, leaders that acknowledge the importance of the employment of people with disability are generally supportive but they are not necessarily actively involved. Also, in a number of these organisations, the leadership will initiate the process of looking at the employment of people with disabilities, but then the human resource department $(\mathrm{HR})$ is tasked with the implementation process. Only one organisation indicated that a senior executive oversees and is responsible for the process.

Leadership commitment has been identified as one of the key success factors for strategies related to the employment of people with disabilities (Silver \& Koopman, 2000 and Thomas \& Hlahla, 2002). Thomas and Hlahla (2002) also point out that it is not enough for the leadership of an organisation to assert that they are committed to the transformation of the organisational culture towards the integration of people with disabilities if they are not prepared to invest resources to make the process a success. Silver and Koopman (2000) suggest that a champion for the process should be appointed, someone who either has a disability, or has a friend or relative with a disability, and holds a senior position in the organisation. As seen in the results of this study, in most of the organisations consulted, the process is largely driven from, and owned by, the human resource department that renders the integration of people with disabilities into the workplace as one of the many human resource interventions. From data collected in this study, it can be seen that the only time that line managers take an interest in the integration of people with disabilities into the workplace is when they have specific targets set for them to achieve, and these are included in their performance agreements. It also appears, however, that in some of the organisations consulted, targets are just set, but there is no monitoring of achievement against these targets, and there are no penalties where they are not being met.

\section{Adaptation of Human Resource Management Practices}

The respondents were asked to identify any modifications that were implemented in their human resource policies and practices in order to accommodate the specific needs of people with disabilities. Their responses were graded using the following criteria:

No modifications: The organisation has not effected any changes to its human resource management policies and practices to accommodate people with disabilities.

Minor modifications: The organisation has made minor adaptations to its human resource management policies and practices in order to accommodate people with disabilities, at a legal compliance level. These policies and practices are only looked at as and when required and mainly only focus on physical barriers.

Major modifications: The organisation has reviewed its current policies and practices to identify any unfair practices that would discriminate against people with disabilities. It has adopted a proactive approach to remove any barriers and actively promotes the employment of people with disabilities (PWDs).

Responses related to this issue are presented in Tables 4 to 8 and are grouped according to the 
human resource management policies and practices related to recruitment and selection, induction and orientation of new staff members, training and career development, performance management, reward and recognition and accessibility of facilities and equipment. In all the tables, where $n$ is not equal to 19 , it is due to the multiple responses received from the respondents.

\section{Recruitment and Selection}

The extent to which participating organisations had adapted their recruitment and selection practices to accommodate and target people with disabilities is presented in Table 4.

Table 4: Recruitment and selection

\begin{tabular}{|l|l|l|}
\hline Extent of modification & N & Nature of modification \\
\hline None & 13 & $\begin{array}{l}\text { In many of the organisations consulted, PWDs have } \\
\text { worked there for many years before EE became an } \\
\text { issue. Mostly, they were there by chance, not because of } \\
\text { an effort on the part of the employer to recruit PWDs. }\end{array}$ \\
\hline Minor & 6 & $\begin{array}{l}\text { Specific positions to target PWDs and advertised as } \\
\text { such } \\
\text { Use of recruitment agencies that specialise in the } \\
\text { placement of PWDs } \\
\text { EE targets to include PWDs } \\
\text { A review of assessment tools used in the recruitment } \\
\text { process }\end{array}$ \\
\hline Major & 1 & $\begin{array}{l}\text { Networking with the disability sector to better understand } \\
\text { their need and identify business opportunities } \\
\text { Research on other assessment tools available for PWDs, } \\
\text { relevant for the different disabilities } \\
\text { Proactively sourcing PWDs to determine how their needs } \\
\text { can be accommodated to make the job application } \\
\text { process fair for them }\end{array}$ \\
\hline
\end{tabular}

The results of the study show that recruitment and selection have received considerable attention from the respondents' organisations. However, there is very little structure in the approach used by most of the organisations that participated in this study, with the exception of two organisations. For many of these organisations, the recruitment drive is only about meeting numerical targets and is not seen as part of an integrated disability strategy that looks at other processes that would make the working experience meaningful for someone with a disability. In the majority of organisations consulted, targets are set but there is no monitoring of achievement against these targets and there are no penalties where they are not being met.

For some organisations, it was viewed as being enough to mention that a position is targeted for previously disadvantaged groups when they advertise positions and if the person that gets appointed into the position happens to have a disability, it was pure coincidence. Others go a step further and mention that people with disabilities are encouraged to apply. But those that are serious about disability equity have followed a process that is in line with the guidelines for a recruitment strategy that Silver and Koopman (2000) proposed. For instance, some organisations in the current study have consulted with people with disabilities during the process of drafting a strategy and policy. This has given the process more credibility in the eyes of its beneficiaries. One of the respondents relayed a comment that was made by one of their employees in this regard "...need to avoid able-bodied people speaking on behalf of people with disabilities about needs that they do not even understand". This shows that people with disabilities do want to be involved in the strategy-formulation process. When they are excluded from the strategy-formulation process, the final strategy may have fundamental flaws due to a lack of understanding of the needs of people with disabilities from those that are involved. 
The Department of Labour's Code of Good Practice on the Employment of People with Disabilities (Republic of South Africa, 2002) and, more recently, the Technical Assistance Guidelines on the Employment of People with Disabilities (Republic of South Africa, 2005) also provide extensive guidelines in terms of how to handle the process of recruiting people with disabilities, right from the job advertisement to the final selection. However, organisations that took part in this study do not seem to be following these guidelines. For example, none of the organisations indicated that when they advertise positions they also make the advertisement available in braille, or on a disc, or tape. Only one respondent indicated that her organisation has actually done a review of its current recruitment process and the assessment tools it uses to ensure that these do not exclude people with disabilities from successfully applying for jobs.

\section{Induction and Orientation}

Once a new person joins an organization, attention needs to be given to the induction and orientation of the new employee so as to facilitate and enhance the entry-experience of the individual. The extent to which aspects related to employees with disabilities is focused on in the induction and orientation strategies of the participating organisations, was explored and the findings reported in Table 5.

\section{Table 5: Induction and orientation of new staff members}

\begin{tabular}{|l|l|l|}
\hline Extent of modification & N & Nature of the modification \\
\hline None & 13 & 2 \\
\hline Minor & 1 & $\begin{array}{l}\text { Disability is discussed as part of the EE presentation } \\
\text { Nemployees encouraged to talk about their disabilities, so } \\
\text { that relevant accommodations can be provided }\end{array}$ \\
\hline Major & 2 & $\begin{array}{l}\text { Interpreter or assistive devices provided } \\
\text { Training of the reception personnel in sign language so that they } \\
\text { can communicate with PWDs when they arrive at reception on } \\
\text { their first day at work }\end{array}$ \\
\hline
\end{tabular}

The induction process is intended for new employees to find out more about the organisation they are going to work for but it is also an opportunity for the organisation to find out more about the individual's special needs and how these can be accommodated. Only one of the organisations consulted indicated that they use the induction process to gain a better understanding of the individual and his or her specific requirements. Some organisations that do have a formal induction programme talk about disability in the induction process, but again only as part of employment equity. At least three organisations were taking active practical steps to assist people with disabilities in the induction process.

\section{Training and Career Development}

Table 6 outlines the extent of the modifications to career and development strategies related to employees with disabilities in the participating organisations. 
Table 6: Training and career development

\begin{tabular}{|l|l|l|}
\hline Extent of Modification & $\mathbf{n}$ & Nature of the modification \\
\hline None & 13 & $\begin{array}{l}\text { All employees are treated equally, or no modifications } \\
\text { have been required because PWDs do not have special } \\
\text { requirements. }\end{array}$ \\
\hline Minor & 1 & $\begin{array}{l}\text { An effort is made to make sure the training venue is } \\
\text { accessible to all. } \\
\text { The training and development strategy is used in growing } \\
\text { PWDs into all levels in the organisation }\end{array}$ \\
\hline Major & 2 & $\begin{array}{l}\text { Making sure that PWDs do not lose out on training } \\
\text { and catering for them according to their specific } \\
\text { needs }\end{array}$ \\
\hline
\end{tabular}

The Code of Good Practice for the Employment of People with Disabilities (Republic of South Africa, 2002) provides guidelines for the training and career advancement of people with disabilities. It is noted, however, that the lack of trainers for people with specific needs has led to the further exclusion of people with disabilities from training. Most of the organisations that participated in the study said that all their employees are treated equally and that they all benefit from the training and development plan of the company. People with disabilities would have individual development plans like everybody else. When the respondents were further probed in terms of what happens if the there is a blind or deaf person that needs to attend training, only three organisations said they make an effort to ensure that people with disabilities do not lose out on training due to inaccessible training facilities. However, contrary to this response, one of the respondents shared an experience where one of the people with disabilities was left out of an HIV/AIDS training course that the company was providing because of inaccessible facilities. Another respondent described a situation where an employee in a wheelchair was invited to attend a diversity workshop that was conducted off the premises of the organisation. The room allocated for this workshop was upstairs and there were no lifts in the building. His colleagues had to carry him up and down for the duration of the workshop, which was embarrassing both for him and the people who had to assist him. None of the organisations referred to the their Skills Development Plans to give an indication of what percentage of the beneficiaries of their learnerships and skills development programmes are people with disabilities.

\section{Performance Management}

Blank and Slipp (1994) are of the view that supervisors are not always able or willing to give objective feedback to employees with disabilities, which creates a barrier to increased/improved performance. In certain cases this has been exacerbated by the non-disclosure of disability, as was the case in some of the organisations that participated in the study as can be seen in Table 7.

Table 7: Performance management

\begin{tabular}{|l|l|l|}
\hline Extent of Modification & $\mathbf{n}$ & Performance Management \\
\hline None & 13 & $\begin{array}{l}\text { In certain cases PWDs have not disclosed their } \\
\text { disabilities and are therefore treated exactly as } \\
\text { everybody else. } \\
\text { It is assumed that a manager that wants to recruit a } \\
\text { PWD has the understanding of how to deal with a } \\
\text { PWD }\end{array}$ \\
\hline Major & 3 & $\begin{array}{l}\text { Education and sensitisation of line managers with } \\
\text { regards to performance management of PWDs and } \\
\text { setting of realistic targets. } \\
\text { Proactively researching the nature of the disability and } \\
\text { providing the information to the line manager and } \\
\text { department. }\end{array}$ \\
\hline 1 & 1 & $\begin{array}{l}\text { Employment equity constitutes 20\% of performance } \\
\text { agreements for line managers }\end{array}$ \\
\hline
\end{tabular}


One of the respondents in this study believed that organisations do not need to be paternalistic and people with disabilities should not be treated as special cases. However, performance management is not one of those disciplines that every manager feels comfortable with, especially where no training for it has been provided. This becomes more of a challenge with people with disabilities where the nature of the disability presents some limitations. This cannot be addressed through the normal performance management system if the managers have not been prepared. Two of the organisations that participated in the study have started to empower their managers in performance managing people with disabilities. They first proactively research the nature of the disability and the extent that it presents a limitation for the person. This information is then passed on to line managers to enable them to set realistic performance targets. One organisation went as far as explicitly linking the management of people from previously disadvantaged backgrounds to the managers' performance contracts.

\section{Accessibility of Facilities}

The extent to which facilities in an organisation are accessible to employees with disabilities is an issue that has numerous practical implications for people with disabilities and can either detract from or enhance an individual's ability to engage fully in the day-to-day activities of that organisation. Table 8 highlights the responses of the representatives of the participating organisations in this regard.

Table 8: Accessibility of facilities

\begin{tabular}{|l|l|l|}
\hline Extent of modification & N & Nature of modification \\
\hline None & 5 & $\begin{array}{l}\text { Special requirements not needed, as PWDS are self- } \\
\text { sufficient }\end{array}$ \\
\hline Minor & 16 & $\begin{array}{l}\text { Availability of ramps and lifts } \\
\text { Designated parking bays, wide enough for cars with } \\
\text { electric wheelchairs } \\
\text { Toilet facilities for PWDs }\end{array}$ \\
\hline 10 & 2 & $\begin{array}{l}\text { Adoption of the "universal access" concept. } \\
\text { Conducting a baseline audit to assess gaps. } \\
\text { Installation of braille buttons and use of voice- } \\
\text { activated lifts and computers. } \\
\text { Upgrade of signage to all facilities. } \\
\text { All staff members to be trained on how to assist } \\
\text { PWDs in cases of emergencies } \\
\text { Coach facility to take people from the parking to the } \\
\text { buildings }\end{array}$ \\
\hline
\end{tabular}

Making facilities more accessible for people with disabilities is one area where considerable progress seems to have been made in terms of reasonable accommodation. It would seem that the organisations in this study have progressed beyond the point of arguing how costly it is to provide reasonable accommodation for people with disabilities. However, it cannot be said whether this is merely a legal compliance response or a genuine openness to remove barriers to the employment of people with disabilities. Almost all the organisations that participated in the study do have ramps and lifts to access their buildings. However, the 'psychological aspect' of these facilities that says "welcome, we want you here" is not always as good. One of the respondents made a comment that although his company has lifts, they are not wide enough, and people in wheelchairs have to use the goods lift. On the question of specialised equipment, those organisations that have blind or deaf people in their employment have provided the required equipment for them to be able to perform their jobs. These range from braille, to voice activated computers and lifts. Most 
of the organisations that participated in this study, however, chose to employ only paraplegics because they do not require special equipment to do their jobs.

\section{Organisational Culture and Employee Attitudes}

Wide-spread ignorance, fear and stereotypes cause people with disabilities to be unfairly discriminated against in society and in the workplace. There are many unfounded assumptions about the abilities and performance of people with disabilities (Republic of South Africa, 2002). A further aim of this study was, therefore, to determine what organisations have done in order to transform the organisational culture and other staff members' attitudes towards people with disabilities. Table 9 outlines the findings in this regard.

Table 9: Types of interventions implemented

\begin{tabular}{|l|l|}
\hline Type of intervention & No of organisations \\
\hline Diversity workshops & 9 \\
\hline No interventions implemented yet & 6 \\
\hline Surveys & 4 \\
\hline Celebration of International Disability Day & 3 \\
\hline
\end{tabular}

From Table 9, it can be seen that two main forms of interventions were cited, namely, surveys and diversity workshops. Four of the organisations indicated that they used surveys to help them gauge the attitudes of employees towards disabilities, which in turn gave them an indication of the types of interventions they needed to implement. The surveys also helped to identify the number of people with disabilities within their organisation and the types of disabilities they have so that the required accommodations could be planned for.

Diversity workshops were cited as the most frequent type of intervention introduced. However, the workshops were on diversity in general, not specifically targeting disability because disability is viewed and treated as part of diversity. Three organisations celebrated the International Day of Disability annually. Two of these organisations stood out in terms of the effort they put into sensitising people about disability. These included, among others, an official launch of a disability statement in the internal newsletter and radio channel. One of these organisations has placed an Employment Equity Consultant in their human resource call centre who can answer questions related to employment equity and, more specifically, disability. The other company extended the celebration of the International Day of Disability to four days, with a variety of 'disruptions' to the workplace so as to give able-bodied employees an experience of some of the challenges people with disabilities have. There was a display of posters with employees of the company that have disabilities throughout the building with quotations such as: 'There's no cure for polio, but there is one for ignorance'; 'Climbing the corporate ladder is tough enough, now try it in a wheelchair'; 'For a guy who can't talk, you'll find that he has a lot to say'. The outcome was a clear recognition of the importance of disability and accepting this as part of the corporate strategy.

\section{Challenges and Benefits Associated with Employing People with Disabilities}

The study aimed to explore the challenges and benefits organisations have experienced in terms of employing people with disabilities. The findings are reported in Tables 10 and 11. 
Table 10: Challenges associated with employing people with disabilities

\begin{tabular}{|c|c|c|}
\hline Nature of the challenges & Specific aspects & $\mathbf{N}$ \\
\hline Environmental & $\begin{array}{l}\text { Inaccessible facilities } \\
\text { Nature of the industry } \\
\text { Inaccessible public transport }\end{array}$ & 3 \\
\hline Attitudinal & $\begin{array}{l}\text { Stigma attached to people with disabilities } \\
\text { Ignorance of issues related to disabilities } \\
\text { Not enough will power and involvement from } \\
\text { top management } \\
\text { Lack of understanding from colleagues and } \\
\text { managers } \\
\text { Management's view that it is just one of HR's } \\
\text { interventions } \\
\text { Disability still perceived as a social } \\
\text { responsibility issue }\end{array}$ & 8 \\
\hline Resources & $\begin{array}{l}\text { Difficulty in finding PWDs who have the right } \\
\text { skills for the jobs available } \\
\text { Costs of accommodation required for various } \\
\text { types of disabilities } \\
\text { Non-disclosure of disability by employees } \\
\text { who have disabilities } \\
\text { Provision of medical aid cover } \\
\text { Not enough role models to learn from }\end{array}$ & 6 \\
\hline
\end{tabular}

It has been acknowledged in almost all the organisations that participated in the study that attitudes towards people with disabilities is the biggest challenge to be overcome. However, most of the organisations surveyed deal with disability as one part of diversity management. The diversity workshops that most of these organisations have implemented were generally on diversity issues, with no particular focus on disability, as acknowledged by the respondents. Thomas and Robertshaw (1999) allude to the fact that it is more difficult to shift paradigms and challenge stereotypes to prepare the organisational context for more sustainable employment equity initiatives. Therefore, the attitudes towards people with disability cannot be addressed by dealing with disability as just part of diversity management alone. Instead, specific focused attention is required in order to make a significant impact in this regard. The cost of accommodation is thus no longer only about Rands and cents spent on making working environments physically accessible to people with disabilities: it is about the time and effort spent trying to change attitudes towards people with disabilities, empowering managers and colleagues on how to deal with people with disabilities.

To address the issue of accommodation in terms of physical facilities and the variety of disabilities, Silver and Koopman (2000) suggest that organisations may have greater success in employing people with disabilities if they focus on one or two types of disabilities. However, care will have to be taken that people with a certain type of disability are not the only ones who benefit in the process, and people with other types of disabilities remaining discriminated against.

The second most frequently mentioned challenge identified by the organisations consulted was that of finding people with disabilities with the right skills for the job. However, none of the organisations consulted in this study have indicated that as part of their strategy for the employment of people with disabilities, they offer bursaries or learnerships for people with disabilities. This would allow people with disabilities to acquire relevant skills that are required in industry, but the organisations would also be able to claim from the 
Department of Labour and National Skills Fund for the development they are offering for people with disabilities (Silver \& Koopman, 2000). Proactive consultations with organisations focusing on specific types of disabilities in the community was not the norm in this sample either and therefore an untapped source of potentially suitable employees.

Lack of voluntary disclosure of disability by employees who do have disabilities has also been noted as a significant challenge. Thomas and Hlahla (2002) note that this may negatively affect the numbers that employers can report in terms of the Employment Equity reports. The current researchers would argue that voluntary disclosure will not happen until people perceive the organisational culture to be one of acceptance and support and one in which diversity is truly valued.

\section{Table 11: Benefits accrued from the employment of people with disabilities}

\begin{tabular}{|l|l|}
\hline Benefits & N \\
\hline No benefits experienced & $\mathbf{7}$ \\
Positive perception that we're a socially responsible company & $\mathbf{5}$ \\
PWDs are more productive and highly committed & $\mathbf{2}$ \\
Contributes to being regarded as an employer of choice & $\mathbf{2}$ \\
Adds to transformation and diversity within the organisation & $\mathbf{2}$ \\
Receiving grants back from the Department of Labour & $\mathbf{1}$ \\
\hline
\end{tabular}

One of the key challenges facing organisations in the global economy is the attraction and retention of talented employees. Employer branding thus becomes a necessity in this context. From the responses highlighted in Table 11, it can be argued that the organisation's approach to dealing with people with disabilities may well have many positive spin-offs towards contributing to the development of a strong organisational employer brand. However, the majority of the respondents could not identify benefits of having employed people with disabilities although they could identify the fact that they have missed out on business opportunities because they do not have people with disabilities in their employment, especially as related to tenders from the government. This is an avenue that clearly requires further exploration.

While the findings of the empirical study have considerable value in terms of providing direction for recommendations related to the human resource management practices and principles applicable to the employment of people with disabilities, a number of limitations do need to be noted.

\section{Limitations of the empirical study}

The following limitations need to be taken into consideration in terms of the generalisability of findings from the empirical study.

* The focus in this study was on private organisations only. It did not look at what is happening in the government, NGOs and the informal sector.

* The study was also limited by the willingness of the organisations that do employ people with disabilities to participate in this study. As a result, the small sample size was an inherent limitation of this study. The results of this study can thus not be generalised to other situations outside this study.

* The research focused only on the people who are responsible for employment equity in their organisations. People with disabilities and their managers were not interviewed to gain their perceptions on the employment of people with disabilities.

* The study focused only on human resource management practices, and did not look at other 
opportunities for empowering people with disabilities such as procurement and social responsibility.

Not withstanding these limitations, a number of recommendations based on the findings of the empirical study can be made in relation to the successful employment of people with disabilities.

\section{RECOMMENDATIONS FOR MANAGEMENT AND HUMAN RESOURCE MANAGEMENT SPECIALISTS}

The following recommendations are informed to a certain extent by current literature in this field but are largely based on the findings of the empirical study that formed the basis for this paper. Practices by the different organisations consulted in the empirical study have been analysed and combined into what the authors propose as a coordinated process to be followed by management and human resource management specialists in an attempt to deal effectively with the challenges related to disability equity.

\section{- Disability Equity ‘Champion’}

It is believed that the appointment of a champion, a senior member of the management team, to be specifically accountable for disability equity, is critical to the success of disability management within any organisation. It has to be someone who is passionate about equity as related to the employment of people with disabilities. This person needs to work in conjunction with the person responsible for employment equity.

\section{- Capacity building}

The extent and nature of previous discrimination against people with disabilities is such that it cannot be dealt with by one person alone. It is therefore proposed that a team of people be nominated to work with the 'champion', preferably in the form of a Disability Equity Forum. The fact that a person or team of people is passionate about disability equity does not pre-suppose that the person has all the knowledge he or she needs to be able to manage disability within the company. The 'champion' and the team must therefore be developed and equipped to a level where they have substantial understanding of the issues around disability equity. It is at this point that a decision should also be made as to which disability organisations and experts to engage and partner with in this process.

\section{- Business case}

The team must then propose a business case for disability equity to top management and show management why it should be spending time, effort and money on disability equity. Employer branding is a key strategy in ensuring organisations have the correct staff to ensure a competitive edge in the global economy. An effective disability equity strategy may well contribute to organisations being viewed as employers of choice. This will help win the buy-in and commitment from management that has been shown to be critical for the successful employment of people with disabilities. This would also help in securing resources and funds to promote the employment of people with disabilities and to engage meaningfully with the spirit of the EEA (Republic of South Africa, 1998).

\section{- Policy and strategy}

A policy on the attraction, placement and retention of people with disabilities needs to be developed. Here, the Department of Labour's Code of Good Practice on the Employment of People with Disabilities (Republic of South Africa, 2002) and the Technical Assistance Guidelines on the Employment of People with Disabilities (Republic of South Africa, 2005) should be referred to and all human resource management practices should be aligned to the recommendations outlined in these documents. Issues to be covered in the policy and implemented in a strategy would include, among other things, the definition of disability and classification of disabilities, proactive recruitment strategies, networking with organisations that deal with the disabled, strategies related specifically to dealing with attitudes towards disability as a form of diversity in the organisation, the modification of policies and practices to ensure that they are free from discrimination in both practice and intent, linking disability equity targets to the performance contracts of line managers, empowering managers to deal with the particular challenges associated with employing people with disabilities, and effective and efficient monitoring processes. 
- Understanding the current status

This step would involve an audit to look at the current figures of people with disabilities within the company, the nature of their disabilities, and the various accommodations these require to be reasonably accommodated. This would also include a survey to gauge the attitudes of staff members towards disability and to encourage those with unknown disabilities to voluntarily disclose their disabilities and the nature of their limitations. Role models in this regard are to be sourced. A detailed review of current practices and policies must then be carried out to identify if there is any covert discrimination against people with disabilities. If any discriminatory practices have been identified, these should be changed, in consultation with the people with disabilities themselves and experts in the field.

- Planning for the future

The policy and strategy related to disability equity should be communicated to the whole organisation. The strategy document should outline exactly how the company is going to integrate people with disabilities into the workplace. A detailed roll-out plan for implementation of interventions to change attitudes and the organisational culture to be more accommodative of people with disabilities must be developed, with accountabilities and time lines. The interventions should include sensitisation of all staff members on how to behave around people with disabilities, empowering line managers on how to manage people with disabilities, and reasonable accommodation interventions. At this stage, the organisation can also decide whether it is going to focus on any particular disabilities or deal with all types of disabilities. Targets can be set to increase the representation of people with disabilities within all levels of the organisation, and these should be included into performance agreements of all managers. A communication plan should also be developed of the current status and the targets that have been set. There should also be discussion on how these will be monitored, and what the ramifications and consequences of non-compliance would be.

- Implementation and monitoring

Continuous monitoring will help to maintain the momentum of the strategy. It should become a sustained process that will ensure a meaningful working experience for people with disabilities over a long period of time with mutual benefits being accrued by both the organisation and the employees with disabilities.

\section{CONCLUSION}

The overall purpose of this paper was to identify and examine human resource management practices related to the employment of people with disabilities. The rationale for the empirical study on which this paper is based was to look at how organisations approach the issue of disability equity, and the extent to which they have aligned their human resource practices to the Code of Good Practice for the Employment of People with Disabilities (Republic of South Africa, 2002). In addition, the challenges experienced by organisations in the employment of people with disabilities have been highlighted in this paper together with the way these organisations have dealt with the challenges. This would help to highlight learning points for those organisations that have not yet started to address the issue of disability equity. Based on the findings of the empirical study and in relation to the relevant literature, a number of recommendations focusing on human resource management practices and principles have been proposed.

In conclusion, it is believed that this paper has highlighted learning points related to the people management practices relevant to the meaningful employment of people with disabilities. It is hoped that these insights will contribute towards meaningful practical changes in our workplaces resulting in disabled people no longer experiencing being 'the most disadvantaged of the disadvantaged' in our South African society and employment settings.

\section{REFERENCES}

Barnes C \& Mercer G. 2003. Disability. Cambridge: Blackwell.

Baldwin ML \& Johnson WG. 2000. Labor market discrimination against men with disabilities in the year of the ADA. Southern Economic Journal, 66(3):548-567.

Blank R \& Slipp S. 1994. Voices of Diversity - Real People Talk about problems and Solutions in a Workplace Where Everyone Is Not Alike. New York: AMACOM. 
Cronan C. 2000. Disabled face obstacles. Tampa Bay Business Journal, 20(35):27-31.

Lehohla PJ. 2003. Census 2001:Census in Brief. Pretoria: Statistics South Africa.

McClain CV \& Lawrence P. 2002. Towards a Barrier-free Society: SAHRC Report 2002. [Online] Available from: http://www.info.gov.za/otherdocs/2002

Neufeldt AH \& Albright AL. 1998. Disability and Self-directed Employment. Ontario: Captus.

Olivier M. 1996. Disability and dependency: a creation of industrial societies? In: J. Swain, V. Finkelstein, M. French, M. and M. Olivier (eds) Disabling Barriers, Enabling Environments. London: Sage.

Republic of South Africa. 1997. White Paper on the Integrated National Disability Strategy. Cape Town: Rustica.

Republic of South Africa. 1998. Employment Equity Act No. 55. Pretoria: Government Printer.

Republic of South Africa. 2002. Code of Good Practice on Employment of People with Disabilities.. [Online] Available from: http://www.labour.gov.za/legislation/code

Republic of South Africa. 2004. Employment Equity Commission Annual Report:2003-2004. [Online] Available from: http://www.labour.gov.za/reports

Republic of South Africa. 2005. Technical Assistance Guidelines on the Employment of People with Disabilities. [Online] Available from: http://www.labour.gov.za/useful-docs

Russel M. 2000. The political economy of disablement. Dollars \& Sense, November:13.

Silver R \& Koopman B. 2000. Successfully Employing People with Disabilities. Cape Town: Business for Good.

Stelzner S. 2003. Restrain the axe-hand - and stay legal. Sunday Times, 23 March 2003:24.

South African Federal Council on Disability. 1999. Conceptual frameworks [Online] Available from: http:www.ability.org.za.

Theobald S. 2003. Around the showroom with a clipboard: The numbers are there, but so is the hum of the Engine. Financial Mail, 27 June:14.

Thomas A \& Hlahla MA. 2002. Factors that influence the employment of people with disabilities in South Africa. South African Journal of Labour Relations, Summer:4 - 32.

Thomas A \& Robertshaw D. 1999. Achieving Employment Equity: A Guide to Effective Strategies. Johannesburg: Knowledge Resources. 